\title{
Crescimento e valor bromatológico de taboa sob condições semiáridas ${ }^{1}$
}

\author{
Jorge Messias Leal do Nascimento ${ }^{2}$, Fernanda Rodrigues Lima da Costa ${ }^{3}$, \\ Mário Adriano Ávila Queiroz ${ }^{3}$, Manoel Eduardo Rozalino Santos ${ }^{4}$
}

\begin{abstract}
Growth and bromatologic value of Typha sp. under semi-arid conditions

Typha sp. plants are rustic and have accelerated development. However, their real growth and potential to animal nutrition are not so well-known. This study aimed to evaluate the shoot biomass production, growth dynamics and chemicalbromatological composition of Typha sp. plants at different cutting heights, under semiarid conditions. A total of four cutting heights $(60 \mathrm{~cm}, 100 \mathrm{~cm}, 140 \mathrm{~cm}$ and $180 \mathrm{~cm})$ were evaluated in a complete randomized design, with five replicates. Plants presented similar production of leaf biomass and heart of palm up to $140 \mathrm{~cm}$ height, with higher leaf accumulation above this value. Its heart of palm grows up to $112.5 \mathrm{~cm}$ and, above this height, only leaf elongation occurs. It is not recommended to cut this plant bellow $140 \mathrm{~cm}$ height, otherwise that can affect the pseudo-stem formation (heart of palm), which supports the leaf biomass accumulation.
\end{abstract}

KEY-WORDS: Typha sp; forage; morphogenetic characteristics.

\section{INTRODUÇÃO}

A região semiárida do Brasil é caracterizada por apresentar irregularidades na distribuição pluviométrica e altas taxas de evapotranspiração, sendo esses os principais entraves para a produção vegetal ao longo do ano. No entanto, Oliveira (2010) menciona que aproximadamente $70 \%$ da composição botânica do bioma Caatinga apresentam potencial forrageiro e significativa participação na composição da dieta dos animais criados na região semiárida do Brasil.

Nesse sentido, torna-se necessária a realização de estudos direcionados a espécies vegetais

\section{RESUMO}

Plantas de taboa (Typha sp.) são rústicas e possuem desenvolvimento acelerado. Porém, seu real crescimento e potencial à nutrição animal são pouco conhecidos. Objetivou-se avaliar a produção de biomassa aérea, dinâmica de crescimento e composição químico-bromatológica de plantas de taboa, em diferentes alturas de corte, sob condições semiáridas. Foram avaliadas quatro alturas de corte $(60 \mathrm{~cm}, 100 \mathrm{~cm}, 140 \mathrm{~cm}$ e $180 \mathrm{~cm}$ ), em delineamento inteiramente casualizado, com cinco repetições. As plantas apresentaram produção de biomassa foliar e palmito semelhantes até $140 \mathrm{~cm}$ de altura, ocorrendo maior acúmulo de folhas após essa altura. O palmito dessa planta cresce até $112,5 \mathrm{~cm}$ e, após essa altura, ocorre apenas alongamento foliar. É recomendado que não se corte a planta antes de $140 \mathrm{~cm}$ de altura, para não prejudicar a formação do pseudocolmo (palmito), que sustenta o acúmulo de biomassa foliar.

PALAVRAS-CHAVES: Typha sp.; forragem; características morfogênicas.

que apresentem potencial forrageiro e que possam contribuir para a redução do défice nutricional dos animais, em especial durante o período seco do ano, permitindo o crescimento sustentável da pecuária, na região semiárida do Brasil. Entre essas espécies, a taboa (Typha sp.) exibe alta produção de biomassa aérea, com valor médio de $7.059 \mathrm{~kg} \mathrm{ha}^{-1}$ de matéria seca (Brasil et al. 2007), o que torna interessante a sua exploração. Esteves et al. (2008) reportam que aproximadamente $73 \%$ das folhas de Typha domingensis Pers. apresentam comprimento variando de $50 \mathrm{~cm}$ a $250 \mathrm{~cm}$, possibilitando maior produção de biomassa da parte aérea.

1. Trabalho recebido em mar./2014 e aceito para publicação em mar./2015 (http://dx.doi.org/10.1590/1983-40632015v4529158).

2. Universidade Federal do Recôncavo da Bahia (UFRB), Centro de Ciências Agrárias, Ambientais e Biológicas, Cruz das Almas, BA, Brasil.E-mail: jorge_messias@ymail.com.

3. Universidade Federal do Vale do São Francisco (Univasf), Câmpus de Ciências Agrárias, Petrolina, PE, Brasil.

E-mails: fernandadeboavista@hotmail.com,marioqueiroz@hotmail.com.

4. Universidade Federal de Uberlândia (UFU), Faculdade de Medicina Veterinária, Uberlândia, MG, Brasil.

E-mail: manoeleduardo@famev.ufu.br. 
Alguns trabalhos destacam o potencial forrageiro de plantas de taboa. Kinupp \& Barros (2008) observaram $16 \%$ de proteína bruta (PB) no palmito da taboa. Nascimento et al. (2014) verificaram teor de fibra em detergente neutro (FDN) de 76,3 \%, nas folhas, e $82,0 \%$, no palmito, e digestibilidade in vitro da FDN de $82,2 \%$ e 78,7 \%, respectivamente para folhas e palmito, como, também, reportaram que folhas de plantas de taboa constituem opção forrageira, devido ao seu valor nutricional. Esses significativos valores proteicos e de digestibilidade da FDN demonstram o potencial da utilização de plantas de taboa na nutrição animal.

Além desses atributos, plantas de taboa constituem fontes de nutrientes, sendo verificados, nas folhas, altos teores de N, P e K (Gonçalves Júnior et al. 2004, Brasil et al. 2007), Ca, Mg, S, Cu, Fe, Mn, Zn, Cr e Cd (Almeida et al. 2007) e Na na parte aérea (Fia et al. 2011). Além disso, Queiroz et al. (2015) afirmam que é possível utilizar plantas de taboa conservadas na forma de silagem, em associação com outra planta forrageira, como a cana-de-açúcar, apresentando aceitável valor nutricional.

A taboa também pode constituir vermífugo natural, reduzindo nematoides gastrintestinais, sem alterar as características hematológicas de caprinos, proporcionando, assim, melhorias aos sistemas de produção animal (Silva et al. 2011). Essa planta pode ser cultivada em locais onde outras espécies vegetais não se adaptariam, ou pelo menos não apresentariam produção de biomassa aérea satisfatória.

Por isso, estudos pioneiros sobre o desenvolvimento dessa planta, como a avaliação de suas características morfogênicas e estruturais, são relevantes. A partir desse conhecimento, é possível, por exemplo, estabelecer práticas de manejo de corte da parte aérea, como a melhor altura da planta no momento do corte. A correta seleção da altura de corte tem potencial para melhorar as taxas de aparecimento e alongamento das lâminas foliares e, com efeito, aumentar a produção de forragem (Silva \& Nascimento Júnior 2006).

Dentre os fatores que podem afetar a morfogênese, produção de forragem, características estruturais e valor bromatológico de plantas forrageiras, destaca-se a altura das plantas no momento do corte. A altura de corte pode afetar o acúmulo de nutrientes de reserva para a rebrota da forrageira. Assim, é necessário o entendimento da interferência desse fator no desenvolvimento vegetal.
Nesse contexto, objetivou-se avaliar a produção de biomassa aérea, dinâmica de crescimento e composição químico-bromatológica de plantas de taboa manejadas com diferentes alturas no momento do corte, sob condições semiáridas.

\section{MATERIAL E MÉTODOS}

O estudo foi realizado em um banhado lacustre temporário, localizado no município de Petrolina (PE) (09²3'S e 40³0'W). Segundo a classificação de Köppen, o clima da região é tropical semiárido, tipo BshW, quente e seco na parte norte e semiárido quente estípico na parte sul. Os dados climáticos registrados durante o período experimental são apresentados na Tabela 1.

As plantas de taboa apresetaram-se estabelecidas naturalmente no referido banhado lacustre, em região de baixada levemente alagada, porém, com as plantas não submersas durante o período de avaliação de 17 de agosto a 13 de outubro de 2010 .

O ensaio foi conduzido em delineamento experimental inteiramente casualizado, com avaliação de quatro alturas de plantas no momento do corte $(60 \mathrm{~cm}$, $100 \mathrm{~cm}, 140 \mathrm{~cm}$ e $180 \mathrm{~cm}$ ), em cinco repetições.

Foram identificadas 20 plantas de taboa, que receberam corte de uniformização a $20 \mathrm{~cm}$ da superfície do solo. Em seguida, todas as plantas foram avaliadas a partir dessa altura de corte, quanto à dinâmica morfogênica, em tempos intercalados de três dias. Ressalta-se que o período total correspondente ao ensaio experimental em campo foi de 57 dias e que, ao atingir as alturas de plantas determinadas como tratamentos $(60 \mathrm{~cm}, 100 \mathrm{~cm}$, $140 \mathrm{~cm}$ e $180 \mathrm{~cm}$ ), houve a realização dos cortes e processamento das amostras. As avaliações foram realizadas em dois cortes/ciclos sequenciais, sendo o valor das variáveis resposta a média entre os dois cortes/ciclos.

Tabela 1. Médias de dados climáticos referentes ao período de 17 de agosto a 13 de outubro de 2010 (Petrolina, PE).

\begin{tabular}{lccc}
\hline \multirow{2}{*}{ Mês } & $\begin{array}{c}\text { Temperatura } \\
\text { média do ar }\end{array}$ & $\begin{array}{c}\text { Umidade } \\
\text { relativa do ar }\end{array}$ & Precipitação \\
\cline { 2 - 4 } & ${ }^{\circ} \mathrm{C}$ & $\%$ & $\mathrm{~mm}$ \\
\hline Agosto & 23,8 & 57,2 & 0,8 \\
Setembro & 25,4 & 52,7 & 4,1 \\
Outubro & 28,7 & 41,7 & 0,0 \\
\hline
\end{tabular}

Fonte: Estação Meteorológica da Univasf, em Petrolina (PE). 
Nesse período, foram realizadas medições das seguintes características estruturais das plantas: número de folhas vivas (NFV) e mortas (NFM), comprimento final da folha (CFFOL) e do palmito (CFPAL) e número de dias de avaliação (DIA). Considerou-se folha morta aquela com senescência presente em mais da metade do seu comprimento. O comprimento da lâmina foliar foi medido do palmito até seu ápice. O comprimento do palmito correspondeu à medida acima do nível dos $20 \mathrm{~cm}$ do rizoma até a inflorescência. A partir dessas mensurações, foram calculadas as seguintes variáveis morfogênicas:

a) Taxa de alongamento foliar (TALFOL): diferença entre o comprimento final das lâminas foliares e o comprimento inicial, dividida pelo número de dias decorridos na avaliação ( $\mathrm{mm}$ planta $\left.{ }^{-1} \mathrm{dia}^{-1}\right)$;

b) Taxa de alongamento do palmito (TALPAL): diferença entre o comprimento final do palmito e seu comprimento inicial, dividida pelo número de dias decorridos na avaliação ( $\mathrm{mm}$ planta ${ }^{-1}$ dia $^{-1}$ );

c) Taxa de senescência foliar (TSENFOL): redução no comprimento da lâmina foliar ainda verde, dividida pelo número de dias de avaliação (mm planta $\left.^{-1} \mathrm{dia}^{-1}\right)$.

d) Taxa de aparecimento foliar (TAPFOL): divisão do número médio de folhas surgidas por planta, pelo número de dias do intervalo de avaliação (folha perfilho-1 $\mathrm{dia}^{-1}$ );

e) Filocrono (FILO): inverso da taxa de aparecimento foliar (dia).

Posteriormente a cada corte, cada planta foi identificada e acondicionada em sacos plásticos. Em seguida, foram separadas em folhas e palmito, pesadas e armazenadas sob refrigeração $\mathrm{a} \pm 4^{\circ} \mathrm{C}$, para posterior análise químico-bromatológica. Foram estimados a matéria mineral (MM) e proteína bruta (PB), segundo Silva \& Queiroz (2002), e a energia bruta (EB), em bomba calorimétrica adiabática, de acordo com metodologia da AOAC (1990). Após a secagem dos componentes morfológicos, obteve-se a massa de folha (MSSFOL) e de palmito (MSSPAL).

Os dados referentes às alturas de corte foram analisados pelo programa computacional SAS, versão 9.1, sendo anteriormente verificada a normalidade dos resíduos pelo teste de Shapiro-Wilk (PROC UNIVARIATE), e as variâncias comparadas por contrastes ortogonais, a $5 \%$, pelo PROC GLM. Posteriormente às análises de contraste, quando significativas, determinou-se a análise de regressão pelo PROC REG, também do mesmo pacote estatístico SAS.

\section{RESULTADOS E DISCUSSÃO}

As características morfogênicas das plantas de taboa foram influenciadas pela altura da planta no momento do corte (Tabela 2), sendo que as taxas de alongamento foliar e o filocrono tiveram efeito linear crescente, enquanto, para a taxa de aparecimento foliar, o efeito foi linear decrescente. A taxa de alongamento do palmito apresentou efeito quadrático: $\hat{\mathrm{Y}}=4,61-0,09 \mathrm{x}+0,0004 \mathrm{x}^{2}\left(\mathrm{R}^{2}=0,38 ; \mathrm{p}=\right.$ 0,0159 ), com valor mínimo de $0,45 \mathrm{~cm}$ planta ${ }^{-1} \mathrm{dia}^{-1}$, quando realizado o corte das plantas com altura de $100 \mathrm{~cm}$ (Tabela 2). No entanto, constata-se que o maior acúmulo de massa de palmito ou pseudocolmo ocorreu após a altura de corte a $140 \mathrm{~cm}$. Isso comprova que, a partir dessa altura, plantas de taboa reduzem a formação de folhas e, por outro lado, aumentam o alongamento foliar. Esse comportamento é semelhante ao encontrado em gramíneas logo

Tabela 2. Características morfogênicas e estruturais de plantas de Typha sp., em função da altura de corte, sob condições semiáridas (Petrolina, PE, 2010).

\begin{tabular}{|c|c|c|c|c|c|c|c|c|}
\hline \multirow{2}{*}{ Variáveis morfogênicas } & \multicolumn{4}{|c|}{ Altura da planta $(\mathrm{cm})$} & \multirow{2}{*}{ EPM } & \multirow{2}{*}{ Regressão } & \multirow{2}{*}{$\mathrm{R}^{2}$} & \multirow{2}{*}{$\mathrm{p}^{*}$} \\
\hline & 60 & 100 & 140 & 180 & & & & \\
\hline TAPF (folha planta-1 dia $^{-1}$ ) & 0,56 & 0,50 & 0,32 & 0,34 & 0,03 & $\hat{\mathrm{Y}}=0,68-0,002 \mathrm{x}$ & 0,32 & 0,008 \\
\hline TALP (mm planta ${ }^{-1}$ dia $\left.^{-1}\right)$ & 0,80 & 0,46 & 0,48 & 2,82 & 0,35 & $\hat{Y}=4,61-0,09 x+0,0004 x^{2}$ & 0,38 & 0,015 \\
\hline TALF (mm planta ${ }^{-1}$ dia $\left.^{-1}\right)$ & 16,08 & 20,56 & 24,66 & 33,98 & 1,78 & $\hat{Y}=6,48+0,14 x$ & 0,69 & $<0,001$ \\
\hline FILO $\left(\right.$ dia folha $\left.{ }^{-1}\right)$ & 1,90 & 2,04 & 3,24 & 3,22 & 0,17 & $\hat{\mathrm{Y}}=1,05+0,01 \mathrm{x}$ & 0,56 & 0,001 \\
\hline \multicolumn{9}{|l|}{ Variáveis estruturais } \\
\hline $\mathrm{CFF}(\mathrm{cm})$ & 29,42 & 42,36 & 78,22 & 107,04 & 7,18 & $\hat{\mathrm{Y}}=16,35+0,67 \mathrm{x}$ & 0,91 & $<0,001$ \\
\hline CFP $(\mathrm{cm})$ & 7,80 & 5,32 & 11,30 & 64,80 & 7,57 & $\hat{Y}=-30,78+0,44 x$ & 0,35 & 0,005 \\
\hline NFV & 6,00 & 6,20 & 7,60 & 7,80 & 0,21 & $\hat{\mathrm{Y}}=4,89+0,01 \mathrm{x}$ & 0,57 & 0,001 \\
\hline
\end{tabular}

TAPF: taxa de aparecimento de folhas; TALP: taxa de alongamento do palmito; TALF: taxa de alongamento de folhas; FILO: filocrono; CFF: comprimento final de folhas; CFP: comprimento final do palmito; NFV: número de folhas vivas; EPM: erro padrão da média. * Significativo ( $\mathrm{p} \leq 0,05)$. 
após o alongamento dos perfilhos, resultando em alongamento foliar.

Estudos avaliando o efeito da altura de capim tifton 85, no momento do corte, nas características morfogênicas foram conduzidos por Pereira et al. (2011), os quais constataram incrementos nas taxas de senescência foliar e número total de folhas por perfilho, com o aumento da altura de corte dessas plantas. Posteriormente, Pereira et al. (2012) verificaram efeitos negativos da altura de corte na redução da razão de área foliar, em plantas de capim-tifton 85, demonstrando que esse fator pode influenciar a taxa de aparecimento de lâmina foliar nas plantas forrageiras. Dessa forma, propõe-se o desenvolvimento de estudos para elucidar a melhor altura das plantas no momento do corte, sem que ocorra interferência na dinâmica de crescimento das mesmas.

A redução da taxa de aparecimento foliar (TAPF), com a altura da planta no momento do corte, pode ser explicada pelo maior percurso que a folha nova tem que fazer entre seu ponto de conexão com o meristema apical e a extremidade do pseudocolmo, formado pelas bainhas das folhas mais velhas, até a sua exposição (Andrade et al. 2008). Esse percurso é maior em plantas com maior altura e, com isso, a folha leva mais tempo até a sua exposição, o que reduz a TAPF, bem como aumenta o filocrono, como demonstrado na Tabela 2 e comprovado estatisticamente pelo $p$ da TAPF e do FILO.

Considerando-se a associação positiva entre altura e idade da planta, Andrade et al. (2008) também verificaram redução da taxa de aparecimento foliar, em função da idade de rebrotação, em plantas de E. pyramidali. Por outro lado, resultados divergentes foram obtidos por Garcez Neto et al. (2002), que constataram que a altura de corte não influencia na taxa de aparecimento de folhas, em plantas de $P$. maximum cv. Mombaça, o que, segundo os autores, pode ser atribuído à reduzida diferença entre as alturas de corte adotadas.

Em relação à taxa de alongamento foliar (TALF), seu aumento, com a altura da planta no momento do corte, pode ser atribuído ao incremento da área foliar em plantas maiores. A planta com menor altura apresentou menor TALF, provavelmente em função da sua reduzida área de folhas e, com efeito, menor interceptação de luz, premissa básica para que as taxas de fotossíntese sejam elevadas. Na medida em que a altura das plantas aumentou, o maior índice de área foliar resultou em maior interceptação de luz pelas plantas, o que estimulou a fotossíntese e o alongamento foliar, bem como pelo palmito.

Não foi verificada taxa de senescência foliar ou número de folhas mortas nas plantas de taboa até o término do período de avaliação. Essa é uma característica interessante, pois confere à folha maior tempo para ser colhida, sem que perdas de forragem por senescência ocorram.

As características morfogênicas da planta determinam as suas características estruturais. Nesse sentido, os comprimentos finais de folha e de palmito, bem como o número de folhas vivas por planta, aumentaram linearmente com a altura da planta no momento do corte, com valores superiores a 7,8 folhas planta-1 (Tabela 2).

Corroborando os resultados do presente estudo, Garcez Neto et al. (2002), avaliando o efeito da altura de corte em plantas de $P$. maximum cv. Mombaça, verificaram incrementos no número de folhas verdes, com o aumento da altura de corte. Além disso, esses autores afirmam que a avaliação do número de folhas expressa o potencial de assimilação de carbono, que está relacionado com a aquisição e translocação de nutrientes para o crescimento vegetativo, particularmente quando estabelecido o processo de senescência.

O manejo racional de plantas com potencial forrageiro é necessário para controlar o período de descanso das plantas, caso contrário, poderão ocorrer aumentos nas taxas de senescência foliar, comprometendo, assim, o desenvolvimento vegetativo. Por isso, estudos envolvendo a influência de alturas da planta no momento do corte sobre o desenvolvimento e produção de plantas forrageiras é importante para a maximização das taxas de acúmulo e produção de biomassa aérea, além de conferir suporte ao manejo racional de pastagens (Andrade et al. 2008).

Os maiores valores de comprimento de folha e de palmito, em função da altura da planta, podem ser justificados pelas superiores taxas de alongamento de folhas e de palmito, nas plantas manejadas com maior altura no momento de corte (Tabela 2). Verificaram-se folhas com alongamento superior a 1,0 m linear.

Para todas as variáveis de massa de forragem em plantas de taboa, constatou-se efeito linear crescente $(p<0,05)$, ocorrendo aumentos da produção de biomassa aérea até os 24,4 dias de avaliação, em plantas com altura de corte de $180 \mathrm{~cm}$ (Figuras 1a e 1b). Similarmente, Aguiar et al. (2000) verificaram aumentos da produção de biomassa seca 
aérea em função da idade de corte, em plantas de $P$. repens. Esses resultados podem ser atribuídos aos maiores alongamentos de folhas e de palmitos, possibilitando incrementos nas taxas fotossintéticas e, consequentemente, maior divisão celular e síntese de novos tecidos. Logo, com o avanço da idade fisiológica da planta, há tendência ao acúmulo de massa de forragem, em detrimento ao menor crescimento da haste ou perfilho.

Contudo, foi verificada maior massa de palmito, em relação à massa de folhas, em plantas de taboa, a partir de $140 \mathrm{~cm}$ (Figura 1b). Tal fato indica que plantas de taboa maiores que $140 \mathrm{~cm}$ podem ter o seu valor nutritivo reduzido. Contrariamente, aquelas plantas de taboa com menos de $140 \mathrm{~cm}$ têm maior potencial de gerar melhor reposta de consumo e desempenho animal, visto que, até essa altura, houve maior produção de massa foliar, em comparação ao palmito (Figuras 1a e 1b).

Houve influência $(\mathrm{p}<0,05)$ da altura de corte na composição químico-bromatológica, proteína bruta (PB) e matéria mineral (MM) de plantas de taboa, porém, sem efeito para o teor de energia bruta, sendo os valores médios obtidos nas folhas e palmito de $2.143,72$ cal g$^{-1}$ e 1.964,88 cal g ${ }^{-1}$, respectivamente. Em relação à proteína bruta, verificou-se que essa foi maior e significativamente superior nas folhas (Figura 2a), apresentando comportamento linear crescente, com valor máximo de $6 \%$, em plantas com altura de corte de $180 \mathrm{~cm}$.

Para o teor de matéria mineral, observaram-se maiores valores médios no palmito $(16,05 \%)$,
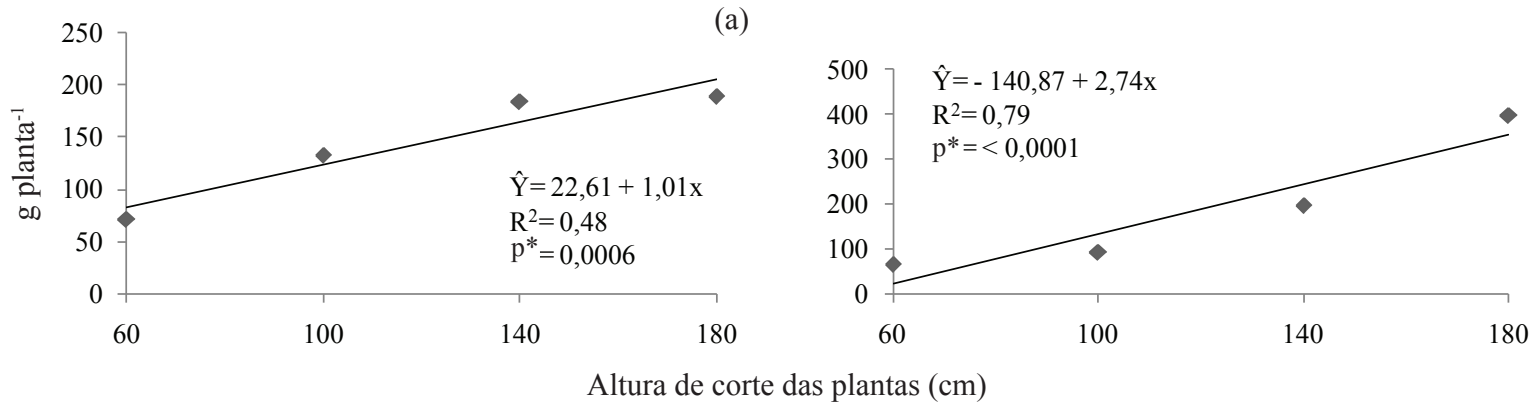

Figura 1. Massa de folhas (a) e de palmito (b), em plantas de Typha sp., em função de alturas de corte, sob condições semiáridas (Petrolina, PE, 2010). * Significativo $(\mathrm{p} \leq 0,05)$.
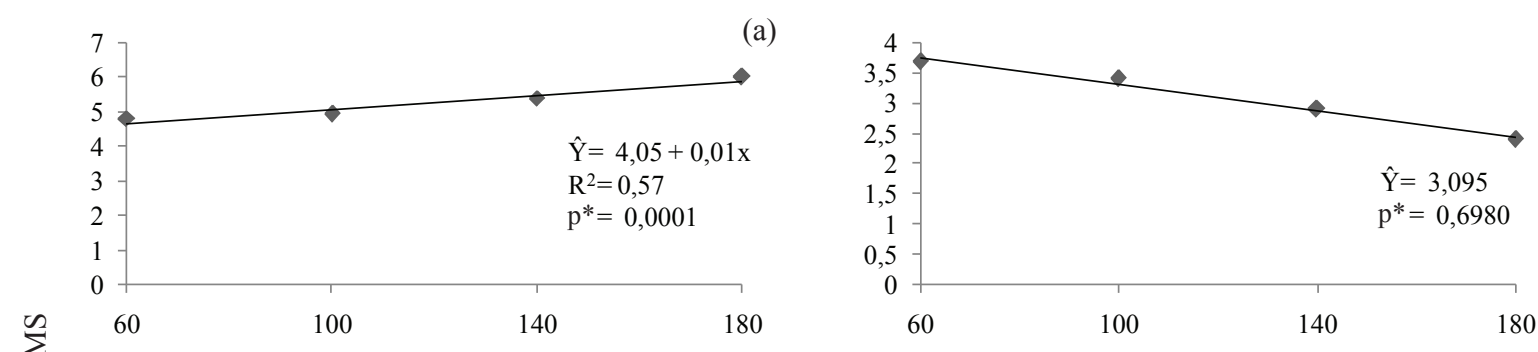

(b)
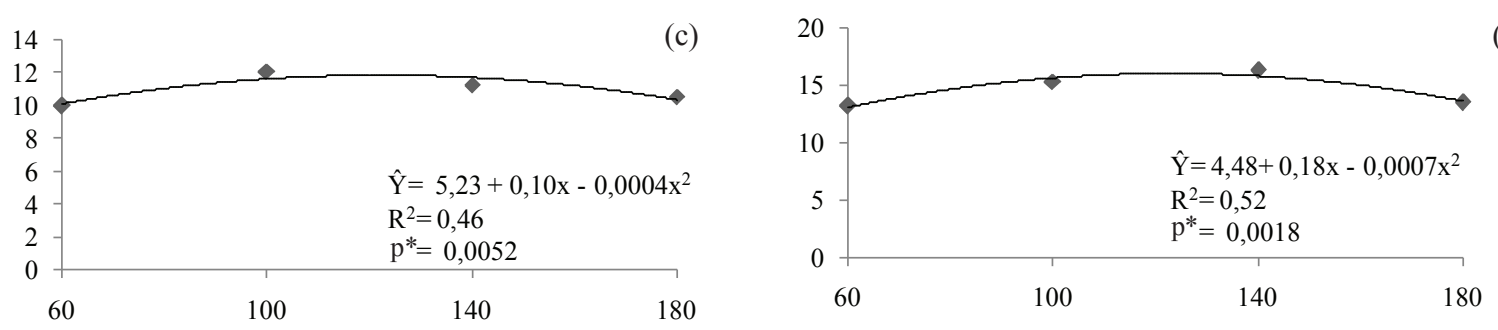

(d)

Figura 2. Teores de proteína bruta nas folhas (a) e palmito (b) e matéria mineral nas folhas (c) e palmito (d) de plantas de Typha sp., em função da altura de corte, cultivadas sob condições semiáridas (Petrolina, PE, 2010). * Significativo $(\mathrm{p} \leq 0,05)$. 
em relação aos teores obtidos nas folhas (11,48 \%) de plantas de taboa, sendo que ambos apresentaram comportamento quadrático, com pontos de máxima de $128,57 \mathrm{~cm}$ e $125,0 \mathrm{~cm}$ de altura de corte das plantas, respectivamente (Figuras $2 \mathrm{c}$ e $2 \mathrm{~d}$ ), obtidos por meio da equação de regressão.

Ressalta-se que os valores observados para os teores de proteína bruta nas folhas de plantas de taboa (Figura 2a) com $180 \mathrm{~cm}$ de altura de corte podem estar associados ao aumento no número de folhas vivas, comprimento final dessas folhas e taxas de alongamento foliar, possibilitando acúmulo de nitrogênio na parte aérea e conferindo a essa planta aceitável potencial forrageiro, tendo-se em vista a sua composição mineral. Corroborando esses resultados, Aguiar et al. (2000) constataram incrementos na produção de proteína bruta, em plantas de $P$. repens, a partir do aumento da idade de corte, o que resulta em renovação da folhagem, possibilitando maior acúmulo de proteína bruta na parte aérea.

Em relação à matéria mineral, diversos trabalhos reportam que plantas de taboa constituem fontes de nutrientes, fato relacionado à sua capacidade de absorção, principalmente em ambientes alagados (Almeida et al. 2007, Brasil et al. 2007), o que viabiliza o seu uso na nutrição animal, possibilitando redução da deficiência nutricional que os animais tendem a passar nos períodos de estiagem, principalmente na região do semiárido brasileiro.

Dessa forma, é possível inferir que plantas de taboa apresentam potenciais benefícios à nutrição animal, podendo ser consideradas plantas com potencial forrageiro, uma vez que foi comprovada a sua alta produção de biomassa aérea, bem como verificado que a mesma constitui fontes de proteína bruta e matéria mineral, tanto na parte aérea como no palmito, em região carente de biomassa para a produção animal. Outro ponto favorável dessa planta é sua velocidade de crescimento.

\section{CONCLUSÕES}

1. Plantas de taboa constituem recurso forrageiro nutricionalmente satisfatório, em termos de minerais, energia e proteína bruta.

2. As plantas de taboa apresentam maior acúmulo de massa foliar após atingirem altura de $140 \mathrm{~cm}$, sendo recomendado que não se faça o corte abaixo dessa altura, como forma de manejo para essa forragem.

\section{REFERÊNCIAS}

AGUIAR, R. S. et al. Produção e composição químicobromatológica do capim-furachão (Panicum repens L.) sob adubação e diferentes idades de cortes. Revista Brasileira de Zootecnia, Viçosa, v. 27, n. 5, p. 833-840, 2000.

ALMEIDA, R. A. et al. Deformação em inflorescência de taboa (Typha angustifolia L.) submetida a esgoto sanitário. Pesquisa Agropecuária Tropical, Goiânia, v. 37, n. 2, p. 125-129, 2007.

ANDRANDE, A. C. et al. Características morfológicas da canarana-ereta-lisa (Echinochoa pyramidalis Lam.) em diferentes idades de rebrotação. Revista Cientifica de Produção Animal, Areia, v. 10, n. 1, p. 37-49, 2008.

ASSOCIATION OF OFFICIAL ANALYTICAL CHEMISTS (AOAC). Official methods of analysis. 11. ed. Washington, DC: AOAC, 1990.

BRASIL, M. S. et al. Plantio e desempenho fenológico da taboa (Typha sp.) utilizada no tratamento de esgoto doméstico em sistema alagado construído. Revista de Engenharia Sanitária e Ambiental, Rio de Janeiro, v. 12, n. 3, p. 266-272, 2007.

ESTEVES, B. S. et al. Allometric relations for Typha domingensis natural populations. Acta Limnologica Brasiliensia, São Paulo, v. 20, n. 4, p. 305-311, 2008.

FIA, F. R. L. et al. Remoção de nutrientes por Typha latifolia e Cynodon spp. cultivadas em sistemas alagados construídos. Revista Ambiente e Água, Taubaté, v. 6, n. 1, p. 77-89, 2011.

GARCEZ NETO, A. F. et al. Respostas morfogênicas e estruturais de Panicum maximum cv. Mombaça sob diferentes níveis de adubação nitrogenada e alturas de corte. Revista Brasileira de Zootecnia, Viçosa, v. 31, n. 5 , p. 1890-1900, 2002.

GONÇALVES JÚNIOR, J. F. et al. The influence of the chemical composition of Typha domingensis and Nymphaea ampla detritus on invertebrate colonization during decomposition in a Brazilian coastal lagoon. Hydrobiologia, Heidelberg, v. 527, n. 1, p. 125-137, 2004.

KINUPP, V. F.; BARROS, I. B. I. Teores de proteína e minerais de espécies nativas, potenciais hortaliças e frutas. Ciência e Tecnologia de Alimentos, Campinas, v. 28, n. 4, p. 846-857, 2008.

NASCIMENTO, J. M. L. et al. Potencial nutricional de plantas de Typha domingensis Pers. como opção forrageira. Revista Brasileira de Ciências Agrárias, Recife, v. 9, n. 2, p. 290-294, 2014.

OLIVEIRA, F. R. B. Valor nutricional e consumo de plantas arbóreas, arbustivas e herbáceas nativas da Caatinga. 2010. 71 f. Dissertação (Mestrado em Ciência 
Animal) - Universidade Federal do Vale do São Francisco, Petrolina, 2010.

PEREIRA, O. G. et al. Características morfogênicas e estruturais do capim-tifton 85 sob doses de nitrogênio e alturas de corte. Revista Brasileira de Zootecnia, Viçosa, v. 40, n. 9, p. 1870-1878, 2011.

PEREIRA, O. G. et al. Crescimento do capim-tifton $85 \mathrm{sob}$ doses de nitrogênio e alturas de corte. Revista Brasileira de Zootecnia, Viçosa, v. 41, n. 1, p. 30-35, 2012.

QUEIROZ, M. A. A. et al. Características fermentativas e bromatológicas de silagens de cana-de-açúcar com taboa. Ciência Rural, Santa Maria, v. 45, n. 1, p. 136-141, 2015.
SILVA, C. F. et al. Avaliação da resposta hematológica dos animais tratados com Typha domingensis Pers. e Operculina hamiltonii sobre nematoides gastrintestinais de caprinos. Ciência e Agrotecnologia, Lavras, v. 35, n. 3, p. 568-574, 2011.

SILVA, C. S.; NASCIMENTO JÚNIOR, D. Ecofisiologia de plantas forrageiras. In: SIMPÓSIO SOBRE MANEJO ESTRATÉGICO DA PASTAGEM, 3., 2006, Viçosa. Anais... Viçosa: UFV, 2006. p. 1-42.

Silva, D. J.; QUEIROZ, A. C. Análise de alimentos: métodos químicos e biológicos. 3. ed. Viçosa: UFV, 2002. 